$3^{\circ}$ INTEGRAR - Congresso Internacional de Arquivos,

Bibliotecas, Centros de Documentação e Museus

"PRESERVAR PARA AS FUTURAS GERAÇÕES"

\title{
Bibliotecários brasileiros pensando o direito: memória dos encontros nacionais de bibliotecários jurídicos (1971-1994)
}

\section{Regina Celi de Sousa Luciana Maria Napoleone}

Eixo temático: Preservação da memória institucional

Palavras-chave: Encontros nacionais. Informação e documentação jurídica. Organização de bibliotecários. Brasil. História.

As congressos e reuniões de bibliotecários são momentos e locais privilegiados para a difusão do conhecimento e para organização de profissionais. Os eventos de documentação e informação jurídica no Brasil são realizados há pouco mais de quatro décadas: o primeiro evento foi realizado durante o VI Congresso Brasileiro de Biblioteconomia e Documentação (CBBD) em 1971, com a participação dos bibliotecários jurídicos presentes, resultando na formação de uma comissão especializada da FEBAB (Federação Brasileira de Associações de Bibliotecários, Cientistas da Informação e Instituições), a CBDJ (Comissão Brasileira de Documentação Jurídica); e o último, também realizado paralelamente ao CBBD, em 2013.

O trabalho representa um esforço inicial de reunir, organizar e sistematizar informações sobre os eventos nacionais de informação e documentação jurídica no Brasil, de maneira a realçar o trabalho colaborativo da comunidade bibliotecária vinculada a área jurídica e que reflete o desenvolvimento e a consolidação da sua atividade junto à comunidade de juízes, juristas, advogados e profissionais de informática. Quanto à metodologia de trabalho, trata-se de texto descritivo, baseado em pesquisas nos 
$3^{\circ}$ INTEGRAR - Congresso Internacional de Arquivos,

Bibliotecas, Centros de Documentação e Museus

"PRESERVAR PARA AS FUTURAS GERAÇÕES"

arquivos da FEBAB, revisão de documentos, atas e artigos, e entrevistas com presidentes e coordenadores dos eventos.

Três momentos representados por três diferentes eventos foram identificados: ENBJ (Encontro Nacional de Bibliotecários Jurídicos, 16 eventos, 1971-1994), ENDIJ (Encontro Nacional de Informação e Documentação Jurídica, 8 edições, 1984-2003), SNDIJ (Seminário Nacional de Documentação e Informação Jurídica, 4 seminários, 2007-2013). Os ENBJs ocorreram paralelamente ao CBBD, organizados pela CBDJ conjuntamente com o Grupo Jurídico do estado; os ENDIJs não estavam relacionados diretamente com a FEBAB, e os SNDIJs são os eventos mais recentes na área jurídica. Além destes eventos de âmbito nacional, existem encontros regionais e reuniões especializadas.

O foco deste trabalho é o primeiro momento, representado pelos ENBJs, cuja sequência está apresentada na Figura 1. Para contextualizar a evolução histórica dos Encontros e demonstrar a persistência do grupo de bibliotecários jurídicos e dos esforços decorrentes promovidos pela comunidade bibliotecária, foram condensadas, no quadro, informações sobre a cidade e data de realização, evento principal da área de Biblioteconomia na qual houve a realização e os objetivos destacados.

\begin{tabular}{|l|l|l|l|l|}
\hline ENBJ & Cidade, UF & Ano & $\begin{array}{l}\text { Evento de } \\
\text { Biblioteconomia }\end{array}$ & Objetivos \\
\hline $1^{\circ}$ ENBJ & $\begin{array}{l}\text { Belo } \\
\text { Horizonte, } \\
\text { MG }\end{array}$ & 1971 & VI CBBD & $\begin{array}{l}\text { Comissão } \\
\text { Documentação e Informação } \\
\text { Jurídica. } \\
\text { Primeira diretoria eleita - ENBJ. }\end{array}$ \\
\hline $2^{\circ}$ ENBJ & $\begin{array}{l}\text { São Paulo, } \\
\text { SP }\end{array}$ & 1972 & II Bienal do Livro & Eleição da 2ª Diretoria \\
\hline
\end{tabular}


$3^{\circ}$ INTEGRAR - Congresso Internacional de Arquivos,

Bibliotecas, Centros de Documentação e Museus

"PRESERVAR PARA AS FUTURAS GERAÇÕES"

\begin{tabular}{|l|l|l|l|l|l|}
\hline $3^{\circ}$ ENBJ & $\begin{array}{l}\text { São Paulo, } \\
\text { SP }\end{array}$ & 1974 & $\begin{array}{l}\text { III Assembleia } \\
\text { das Comissões } \\
\text { Permanentes da } \\
\text { FEBAB }\end{array}$ & $\begin{array}{l}\text { Apresentação de trabalhos. } \\
\text { Proposta de Elaboração de } \\
\text { Catálogo Coletivo de Periódicos } \\
\text { em Direito. }\end{array}$ \\
\hline $4^{\circ}$ ENBJ & Brasília, DF & 1975 & VIII CBBD & $\begin{array}{l}\text { Eleição de nova diretoria. } \\
\text { Apresentação de publicações: } \\
\text { Catálogo Coletivo de Periódicos } \\
\text { da área jurídica (Brasília, Minas } \\
\text { Gerais, Rio Grande do Sul); Guia } \\
\text { Preliminar das bibliotecas } \\
\text { jurídicas do Rio de Janeiro. }\end{array}$ \\
\hline $5^{\circ}$ ENBJ & Rio de & 1976 & $\begin{array}{l}\text { Conferência } \\
\text { Janeiro, RJ } \\
\text { Classificação }\end{array}$ & $\begin{array}{l}\text { Comemoração dos 149 anos de } \\
\text { Fundação do ensino jurídico no } \\
\text { Brasil. } \\
\text { Homenagem a Bastos Tigres, } \\
\text { patrono dos bibliotecários } \\
\text { brasileiros. } \\
\text { Grupo São Paulo edita 2o volume } \\
\text { do Catálogo Coletivo de } \\
\text { Periódicos em Direito. }\end{array}$ \\
\hline $6^{\circ}$ ENBJ & Porto & 1977 & IX CBBD & $\begin{array}{l}\text { Apresenta trabalho: O sistema de } \\
\text { informações jurídicas-tributária do } \\
\text { Ministério da Fazenda: histórico e } \\
\text { situação atual. } \\
\text { Desativação do GBIDJ de São } \\
\text { Paulo. }\end{array}$ \\
\hline
\end{tabular}


$3^{\circ}$ INTEGRAR - Congresso Internacional de Arquivos,

Bibliotecas, Centros de Documentação e Museus

"PRESERVAR PARA AS FUTURAS GERAÇÕES"

\begin{tabular}{|c|c|c|c|c|}
\hline $7^{\circ}$ ENBJ & $\begin{array}{ll}\text { São Paulo, } \\
\text { SP }\end{array}$ & 1978 & $\begin{array}{l}\text { IV Assembleia } \\
\text { das Comissões } \\
\text { Permanentes da } \\
\text { FEBAB }\end{array}$ & $\begin{array}{l}\text { Todos os Grupos passam a } \\
\text { denominar-se: Grupos de } \\
\text { Bibliotecários em Informação e } \\
\text { Documentação Jurídica - GBIDJ. } \\
\text { Reativação do GBIDJ de São } \\
\text { Paulo. } \\
\text { Desativação do GBIDJ de Brasília } \\
\text { e Pernambuco. } \\
\text { Reativação do GBIDJ do Pará, } \\
\text { como subgrupo do Grupo de } \\
\text { Bibliotecários em Informação e } \\
\text { Documentação em Ciências } \\
\text { Sociais e Humanidades do Pará. } \\
\text { Rio Grande do Sul edita o } \\
\text { Catálogo Coletivo de Periódicos } \\
\text { Jurídicos. }\end{array}$ \\
\hline 8 ENBJ & Curitiba, PR & 1979 & X CBBD & $\begin{array}{l}\text { Apresentação dos trabalhos: O } \\
\text { Bibliotecário no Brasil: } \\
\text { configuração para a defesa } \\
\text { profissional de direito e de fato } \\
\text { com enfoque interdisciplinares, } \\
\text { institucionais e sobre o CRB } 7 \text {. } \\
\text { No período funcionavam apenas } \\
4 \text { GBIDJ: Bahia, Minas Gerais, } \\
\text { Rio Grande do Sul e São Paulo. }\end{array}$ \\
\hline
\end{tabular}


$3^{\circ}$ INTEGRAR - Congresso Internacional de Arquivos,

Bibliotecas, Centros de Documentação e Museus

"PRESERVAR PARA AS FUTURAS GERAÇÕES"

\begin{tabular}{|c|c|c|c|c|}
\hline $9^{\circ}$ ENBJ & $\begin{array}{l}\text { Salvador, } \\
\text { BA }\end{array}$ & 1980 & $\begin{array}{l}1 \text { 10 Congresso } \\
\text { Latino Americano } \\
\text { de } \\
\text { Biblioteconomia } \\
\text { e Documentação }\end{array}$ & $\begin{array}{l}\text { CBDJ edita o informativo } \\
\text { FEBAB/CBDJ. } \\
\text { GBIDJ Bahia edita: Perfil do } \\
\text { usuário jurídico; Periódicos de } \\
\text { Direito e Legislação: catálogo } \\
\text { coletivo; Cadastramento de } \\
\text { Bibliotecas } \\
\text { Questionário para avaliação de } \\
\text { acervos jurídicos das bibliotecas } \\
\text { baianas e boa utilização. } \\
\text { GBIDJ do Rio Grande do Sul } \\
\text { edita: Catálogo Coletivo de } \\
\text { Periódicos em Direito. } \\
\text { Inicio do GBIDJ em Mato Grosso } \\
\text { do Sul }\end{array}$ \\
\hline $\begin{array}{l}10^{\circ} \\
\text { ENBJ }\end{array}$ & $\begin{array}{l}\text { João } \\
\text { Pessoa, PB }\end{array}$ & 1982 & XI CBBD & $\begin{array}{l}\text { Contatos para ativar novos GBIDJ } \\
\text { em Alagoas, Amazonas, Ceará, } \\
\text { Espírito Santo, Paraíba, Paraná, } \\
\text { Rio Grande do Norte e Santa } \\
\text { Catarina. } \\
\text { Desativação do GBIDJ de Brasília } \\
\text { e Rio de Janeiro. } \\
\text { Ativação do GBIDJ de Mato } \\
\text { Grosso do Sul. }\end{array}$ \\
\hline
\end{tabular}


$3^{\circ}$ INTEGRAR - Congresso Internacional de Arquivos,

Bibliotecas, Centros de Documentação e Museus

"PRESERVAR PARA AS FUTURAS GERAÇÕES"

\begin{tabular}{|c|c|c|c|c|}
\hline $\begin{array}{l}11^{\circ} \\
\text { ENBJ }\end{array}$ & $\begin{array}{l}\text { Camboriú, } \\
\text { SC }\end{array}$ & 1985 & XII CBBD & $\begin{array}{l}\text { Apresentação do estudo sobre o } \\
\text { Sindicalismo na profissão do } \\
\text { Bibliotecário. } \\
\text { GBIDJ do Rio Grande do Sul } \\
\text { edita o Catálogo Coletivo de } \\
\text { Periódico Jurídico. } \\
\text { GBIDJ de Santa Catarina edita o } \\
\text { Cadastro das Bibliotecas e/ou } \\
\text { Centros de Documentação e } \\
\text { Informação na área jurídica. } \\
\text { GBIDJ de São Paulo edita o Guia } \\
\text { de Bibliotecas Jurídicas do } \\
\text { Estado de São Paulo e de Obras } \\
\text { de referência em Direito. }\end{array}$ \\
\hline $\begin{array}{l}12^{\circ} \\
\text { ENBJ }\end{array}$ & Vitória, ES & 1985 & XIII CBBD & --- \\
\hline $\begin{array}{l}13^{\circ} \\
\text { ENBJ }\end{array}$ & Recife, PE & 1987 & XIV CBBD & --- \\
\hline $\begin{array}{l}14^{\circ} \\
\text { ENBJ }\end{array}$ & $\begin{array}{l}\text { Rio } \mathrm{de} \\
\text { Janeiro, RJ }\end{array}$ & 1989 & XV CBBD & --- \\
\hline $\begin{array}{l}15^{\circ} \\
\text { ENDJ }\end{array}$ & $\begin{array}{l}\text { Salvador, } \\
\text { BA }\end{array}$ & 1991 & XVI CBBD & --- \\
\hline
\end{tabular}


$3^{\circ}$ INTEGRAR - Congresso Internacional de Arquivos,

Bibliotecas, Centros de Documentação e Museus

"PRESERVAR PARA AS FUTURAS GERAÇÕES"

\begin{tabular}{|c|c|c|c|c|}
\hline $\begin{array}{l}\text { l6o } \\
\text { ENDJ } \\
\text { Seminári } \\
\text { nformaç da } \\
\text { áo écnica } \\
\text { Escritório } \\
\text { Advocaci } \\
\text { a de }\end{array}$ & $\begin{array}{l}\text { Belo } \\
\text { Horizonte, } \\
\text { MG }\end{array}$ & 1994 & $\begin{array}{l}2^{\circ} \text { Congresso } \\
\text { Latino Americano } \\
\text { de } \\
\text { Biblioteconomia } \\
\text { e Documentação } \\
17^{\circ} \text { CBBD }\end{array}$ & $\begin{array}{l}\text { Os eventos têm como objetivo } \\
\text { reunir os profissionais da área } \\
\text { jurídica para troca de } \\
\text { experiências e informações. }\end{array}$ \\
\hline
\end{tabular}

Figura 1 - Encontro Nacional de Bibliotecários Jurídicos

O papel da FEBAB foi fundamental neste primeiro período dos encontros na área jurídica. Apoiados na estrutura organizacional da Federação e das Associações de Bibliotecários dos estados, os grupos de bibliotecários jurídicos foram se moldando e se estruturando, e configurando um movimento institucionalizado em órgãos de representação profissional, fato que contribuiu para o fortalecimento da atividade profissional perante as estruturas sociais e econômicas da sociedade.

O suporte institucional foi fundamental para que os eventos jurídicos ocorressem, o que se evidenciou pela realização simultânea ou em paralelo a eventos gerais da área. A CBDJ e os Grupos Jurídicos foram os articuladores dos ENBJ; os Grupos Jurídicos colaboraram para a realização dos ENDIJ. Os SNDIJ tiveram o suporte da ABDF (Associação de Bibliotecários do Distrito Federal) e, na última edição, também de Grupos Jurídicos. 
$3^{\circ}$ INTEGRAR - Congresso Internacional de Arquivos,

Bibliotecas, Centros de Documentação e Museus

"PRESERVAR PARA AS FUTURAS GERAÇÕES"

A reativação da CBDJ enquanto Comissão Especializada da FEBAB, mostra-se um elemento estratégico para catalisar as iniciativas dos bibliotecários jurídicos nos diversos estados brasileiros, para oferecer infraestrutura para realização de atividades e ações, eventos e disseminação do conhecimento produzido na área, ao mesmo tempo em que resgata a história da Comissão e une a história dos esforços realizados com a atuação dos profissionais de hoje. Num caminho de mão dupla, fortalece ao mesmo tempo a profissão e os profissionais, a Federação e os Grupos Jurídicos. Considerando que o movimento associativo bibliotecário no Brasil tem se defrontado com o desafio de sobrevivência com o pequeno volume de profissionais associados e a dificuldade de encontrar e formar lideranças, uma recomendação é estudar a participação de integrantes de associações de bibliotecários, grupos jurídicos, representantes indicados (no caso de não haver Associação ou GIDJ) e grupos especializados na Comissão.

\section{Referências}

Arquivo da FEBAB. Arquivo pessoal de Regina Céli de Sousa.

\section{Informações das autoras}

\section{Regina Celi de Sousa}

Machado Meyer Advogados

Email: sousa@machadomeyer.com.br

\section{Luciana Maria Napoleone}

Tribunal Regional Federal da 3ㄹ Região

Email: lunapoleone@gmail.com

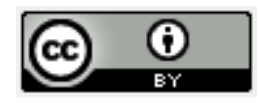

